\title{
Protocol
}

\section{Setting up Schizosaccharomyces pombe Crosses/Matings}

\author{
Karl Ekwall ${ }^{1,3}$ and Geneviève Thon ${ }^{2}$ \\ ${ }^{1}$ Department of Biosciences and Nutrition, Karolinska Institute, Stockholm SE-141 83, Sweden; ${ }^{2}$ Department \\ of Biology, University of Copenhagen, Copenhagen DK-2200, Denmark
}

Here we provide methods for setting up standard crosses with Schizosaccharomyces pombe strains. All strain genotypes and pedigrees should be recorded in a laboratory strain book. Matings between two haploid strains of interest are induced on solid medium poor in nitrogen. Usually, sporulation agar (SPA) plates are preferred, but for difficult matings it is advisable to try several mating media in parallel because one medium might allow for more efficient mating. Protoplast fusion can be used to produce zygotes from sterile mutants that fail to mate.

MATERIALS

Reagents

It is essential that you consult the appropriate Material Safety Data Sheets and your institution's Environmental Health and Safety Office for proper handling of equipment and hazardous materials used in this protocol.

RECIPES: Please see the end of this protocol for recipes indicated by $<R>$. Additional recipes can be found online at http://cshprotocols.cshlp.org/site/recipes.

Agar

$\mathrm{CaCl}_{2}(0.1 \mathrm{M})$

Glucanex ( $\beta$-glucanase; Novozymes)

Prepare a fresh $3 \mathrm{mg} / \mathrm{mL}$ solution in $0.65 \mathrm{~m} \mathrm{KCl}$ for each application.

$\mathrm{KCl}(0.65 \mathrm{M})$

Media

Selection medium containing $1.2 \mathrm{M}$ sorbitol appropriate for experimental strains

Sporulation agar (SPA) medium $<\mathrm{R}>$

Supplements may be needed for auxotrophic strains (see Step 2).

Yeast extract with supplements (YES) $<\mathrm{R}>$

Omit lysine from YES if growing arginine auxotrophs.

Polyethylene glycol (PEG 6000; 30\%)

S. pombe strains appropriate for experimental goals

Genetic manipulations require a precise knowledge of the genotypes of parental and progeny strains. It is essential to keep track of these by giving each strain a name (usually a number in a strain collection) and by writing down its complete genotype, stock date, PubMed references for parental strains, investigators name, and other notes of interest, such as temperature sensitivity, etc. This information should be kept in a strain book (and/or electronically). This greatly simplifies the communication of strain information and of handling strain requests after the publication of new strains.

${ }^{3}$ Correspondence: karl.ekwall@ki.se

From the Fission Yeast collection, edited by lain M. Hagan, Antony M. Carr, Agnes Grallert, and Paul Nurse.

(C) 2017 Cold Spring Harbor Laboratory Press

Cite this protocol as Cold Spring Harb Protoc; doi:10.1101/pdb.prot091694 
K. Ekwall and G. Thon

Sorbitol (1.2 M)

Water (distilled, sterile)

Equipment

Applicator sticks (long, wooden, autoclaved; or disposable plastic inoculation loops, sterile)

Centrifuge to hold swing out rotor for $50-\mathrm{mL}$ screw-cap tubes

Flasks $(250 \mathrm{~mL})$

Hemocytometer

Phase-contrast light microscope equipped with $40 \times$ objective and $10 \times$ eyepiece

Plate incubator

Shaking incubator

Toothpicks (flat and sharp, autoclaved)

Tubes (50 mL, screw-cap, sterile)

\section{METHOD}

\section{Standard Crosses}

1. Grow strains of opposite mating type that are to be crossed.

Strains should be freshly grown overnight, either in $5 \mathrm{~mL}$ of YES liquid cultures or as a patch on a YES plate. Usually $h^{+}$and $h^{-}$mating-type strains are used. For details on culturing S. pombe, see Introduction: Growth and the Environment of Schizosaccharomyces pombe (Petersen and Russell 2016).

2. Mix equal amounts of cells of the two strains in a drop of sterile water on an SPA plate using an inoculating loop or a flat toothpick.

Cells should be taken directly from the YES plate or, for liquid cultures, after harvesting by centrifugation. Several crosses can be set up on the same 9-cm diameter plate.

When crossing homothallic $h^{90}$ strains with $h^{-}$or $h^{+}$strains, use ratios of $1: 3$ for $h^{90}$ to $h^{+}$or $h^{-}$cells to minimize self-mating.

If strains are auxotrophic, add the necessary supplements to the sporulation plate to a final concentration of $40 \mu \mathrm{g} / \mathrm{mL}$. Do not exceed this level or mate on plates containing all amino acids because the nitrogen from the amino acids will be catabolized, which reduces the efficiency of $G_{1}$ arrest and, therefore, mating efficiency.

3. Allow the cell suspensions to dry completely. Invert the plate and incubate for $2-3 \mathrm{~d}$ below $30^{\circ} \mathrm{C}$ until asci have formed.

4. Monitor the formation of asci by removing some cells and examining them under a light microscope.

See Troubleshooting.

\section{Crossing by Protoplast Fusion}

Some mutants are completely sterile and cannot be studied by routine crosses. However, it is possible to force such crosses by digesting the cell wall to form protoplasts that can then fuse to form a zygote (Nadin-Davis and Nasim 1990).

5. Grow each of the two strains in $50 \mathrm{~mL}$ of YES medium in $250-\mathrm{mL}$ flasks with shaking at $30^{\circ} \mathrm{C}$ to logarithmic phase $\left(2-3 \times 10^{6}\right.$ cells $\left./ \mathrm{mL}\right)$.

For details on culturing S. pombe, see Introduction: Growth and the Environment of Schizosaccharomyces pombe (Petersen and Russell 2016).

6. Transfer cells to 50-mL screw-cap tubes and harvest cells by centrifugation for $3 \mathrm{~min}$ at $3200 \mathrm{~g}$.

7. Wash cells by resuspension in $10 \mathrm{~mL}$ of $0.65 \mathrm{M} \mathrm{KCl}$ followed by centrifugation for $3 \mathrm{~min}$ at $3200 \mathrm{~g}$. 
8. Discard supernatant and resuspend cells in $5 \mathrm{~mL}$ of $0.65 \mathrm{~m} \mathrm{KCl}$ containing $3 \mathrm{mg} / \mathrm{mL}$ Glucanex. Do not vortex the cells/protoplasts.

9. Incubate cells for $20-30 \mathrm{~min}$ at $30^{\circ} \mathrm{C}$ until protoplasts form. Check for protoplast formation by observing a $5-\mu \mathrm{L}$ aliquot on a hemocytometer under a phase-contrast microscope. Protoplasts appear rounded.

10. When $>90 \%$ of cells have formed protoplasts, add $10 \mathrm{~mL}$ of $1.2 \mathrm{M}$ sorbitol and then harvest by centrifugation at $1250 \mathrm{~g}$ for $3 \mathrm{~min}$.

11. Discard the supernatant, and resuspend protoplasts in $2 \mathrm{~mL}$ of $1.2 \mathrm{M}$ sorbitol. If the two strains are ready at slightly different times, the first strain can be left in sorbitol at room temperature.

12. Combine the two protoplast samples and mix by gentle pipetting up and down. Cut the end of a 1-mL pipette tip to reduce sheer forces during mixing

13. Harvest the protoplasts by centrifugation for $3 \mathrm{~min}$ at $1250 \mathrm{~g}$.

14. Mix nine parts $30 \%$ PEG 6000 with one part $0.1 \mathrm{M} \mathrm{CaCl}_{2}$. Resuspend the protoplasts in $1 \mathrm{~mL}$ of the PEG- $-\mathrm{CaCl}_{2}$ mixture.

15. Incubate for $30 \mathrm{~min}$ at room temperature.

16. Melt $1 \%$ agar in $10 \mathrm{~mL}$ of an appropriate selective growth medium made with $1.2 \mathrm{M}$ sorbitol. Cool to $<45^{\circ} \mathrm{C}$. Add to the protoplast mixture.

17. Pour the $1 \%$ agar growth medium incorporating the protoplasts onto an appropriate selection plate containing $1.2 \mathrm{M}$ sorbitol.

Do not use any physical means of spreading (beads or glass rod) as this will burst the protoplasts.

18. Incubate the plate for $2-3 \mathrm{~d}$ below $30^{\circ} \mathrm{C}$ until asci have formed.

Problem: (Step 4): Some mutants mate inefficiently using the standard protocol.

Solution: Mix equal numbers of cells of each strain from mid-log phase cultures grown in minimal medium or MSL medium $\left(2-5 \times 10^{6}\right.$ cells $\left./ \mathrm{mL}\right)$. Place droplets of the cell mixture onto different types of mating medium, that is, ME, MSA, SPA, or EMM-N plates (see Introduction: Growth and the Environment of Schizosaccharomyces pombe [Petersen and Russell 2016]) and incubate overnight. Efficiency of mating is often improved on one or more of these media. It may also be helpful to use a higher ratio of mutant to wild-type cells in the cross (e.g., a 3:1 ratio). A further way to increase efficiency can be to reduce the number of auxotrophic markers in the strains.

Sporulation Agar (SPA) Medium

\begin{tabular}{lrc} 
Reagent & Quantity (for $1 \mathrm{~L})$ & Final concentration \\
\hline Glucose & $10 \mathrm{~g}$ & $55.5 \mathrm{mM}$ \\
$\mathrm{KH}_{2} \mathrm{PO}_{4}$ & $1 \mathrm{~g}$ & $7.3 \mathrm{mM}$ \\
Vitamins $(1000 \times)<\mathrm{R}>$ & $1 \mathrm{~mL}$ & $1 \times$ \\
Agar & $20 \mathrm{~g}$ & $20 \mathrm{~g} / \mathrm{L}$ \\
$\mathrm{H}_{2} \mathrm{O}$ & to $1 \mathrm{~L}$ &
\end{tabular}

To prepare SPA medium (Munz and Leupold 1970), combine the ingredients listed above. Sterilize by autoclaving at $10 \mathrm{psi}$ for $15 \mathrm{~min}$. Store at $4^{\circ} \mathrm{C}$. 
K. Ekwall and G. Thon

Vitamins (1000x)

Reagent

Quantity (for 1 L)

Final concentration

Pantothenic acid

$1 \mathrm{~g}$

$4.20 \mathrm{~mm}$

Nicotinic acid

$10 \mathrm{~g}$

$81.2 \mathrm{~mm}$

Inositol

$10 \mathrm{~g}$

$55.5 \mathrm{~mm}$

Biotin

$10 \mathrm{mg}$

$40.8 \mu \mathrm{M}$

Store at $4^{\circ} \mathrm{C}$.

Yeast Extract with Supplements (YES)

Reagent

Amount to add (1 L)

Glucose $30 \mathrm{~g}$

Yeast extract

Adenine

$0.2 \mathrm{~g}$

Uracil

$0.2 \mathrm{~g}$

Histidine

$0.2 \mathrm{~g}$

Leucine

$0.2 \mathrm{~g}$

Lysine

$0.2 \mathrm{~g}$

Agar (for solid medium only)

$20 \mathrm{~g}$

$\mathrm{H}_{2} \mathrm{O}$

to $1 \mathrm{~L}$

Prepare $1 \mathrm{~L}$ of YES by combining the reagents listed above. Sterilize by autoclaving at $10 \mathrm{psi}$ for $15 \mathrm{~min}$. Store at $4^{\circ} \mathrm{C}$. (Note that the yeast extract contains sufficient thiamine to repress $n m t 1$ promoters.)

\section{ACKNOWLEDGMENTS}

We acknowledge Agnes Grallert for providing the protoplast fusion protocol. K.E. was supported by the Swedish Cancer Society and the Swedish Research Council. G.T. was supported by the Novo Nordisk Foundation and the University of Copenhagen Center of Excellence MolPhysX.

\section{REFERENCES}

Munz P, Leupold U. 1970. Characterization of ICR-170-induced mutations in Schizosaccharomyces pombe. Mutat Res 9: 199-212.

Nadin-Davis SA, Nasim A. 1990. Schizosaccharomyces pombe ras1 and byr1 are functionally related genes of the ste family that affect starva- tion-induced transcription of mating-type genes. Mol Cell Biol 10: 549-560.

Petersen J, Russell P. 2016. Growth and the environment of Schizosaccharomyces pombe. Cold Spring Harb Protoc doi: 10.1101/pdb.top079764. 


\section{Setting up Schizosaccharomyces pombe Crosses/Matings}

Karl Ekwall and Geneviève Thon

Cold Spring Harb Protoc; doi: 10.1101/pdb.prot091694

\begin{tabular}{cc}
$\begin{array}{r}\text { Email Alerting } \\
\text { Service }\end{array}$ & Receive free email alerts when new articles cite this article - click here. \\
\hline $\begin{array}{c}\text { Subject } \\
\text { Categories }\end{array}$ & $\begin{array}{c}\text { Browse articles on similar topics from Cold Spring Harbor Protocols. } \\
\text { Yeast (288 articles) } \\
\\
\text { Yeast Genetics (135 articles) }\end{array}$ \\
\hline
\end{tabular}

